\title{
Muon beams at PSI
}

\author{
R. Abela, F. Foroughi, D. Renker \\ Paul Scherrer Institute, CH-5232 Villigen PSI, Switzerland
}

5 December 1991 all can be used as low energy - cloud, surface and subsurface - muon beams.

\section{Muon beam $\mu \mathrm{E} 1$}

Up to now this beam line shared the first quadrupoles and a bending magnet with the $\pi \mathrm{E} 1$ channel and therefore the polarity and the momentum of the muons could only be changed in agreement with the users of the $\pi \mathrm{E} 1$. We decoupled these channels by installing half quadrupoles, focussing elements made of two poles - half of a quadrupole - and an iron mirror plate, which produce a perfect quadrupole field in half of the aperture [4] (Fig. 2).

We reinstalled the first coil of the superconducting solenoid, which tended to quench in earlier times because it was heated by the nearby beam dump, and built in new vacuum chambers and collimators. This will give higher muon rates and less contamination with pions and electrons. See Table 1 for rates and other beam properties. A flexible muon extraction system will allow to swith from SINDRUM II, which is permanently installed, to an other experiment within short time.

\section{Pion beam $\pi \mathrm{E} 1$}

As described in the previous section this channel became now independent from the $\mu \mathrm{E} 1$ beam line by a similar triplett of half quadrupoles for the first focussing. By greater bending angles in the dipoles, which forced us to introduce a third dipole in order to keep the geometry of the area, the momentum resolution of $\pi \mathrm{E} 1$ was improved. Since there is no more any window in the vacuum system between the production target and the experiment, this channel can now be used as a surface or low energy cloud muon beam, but the expected high contamination with electrons or positrons will always call for an electrostatic separator. 


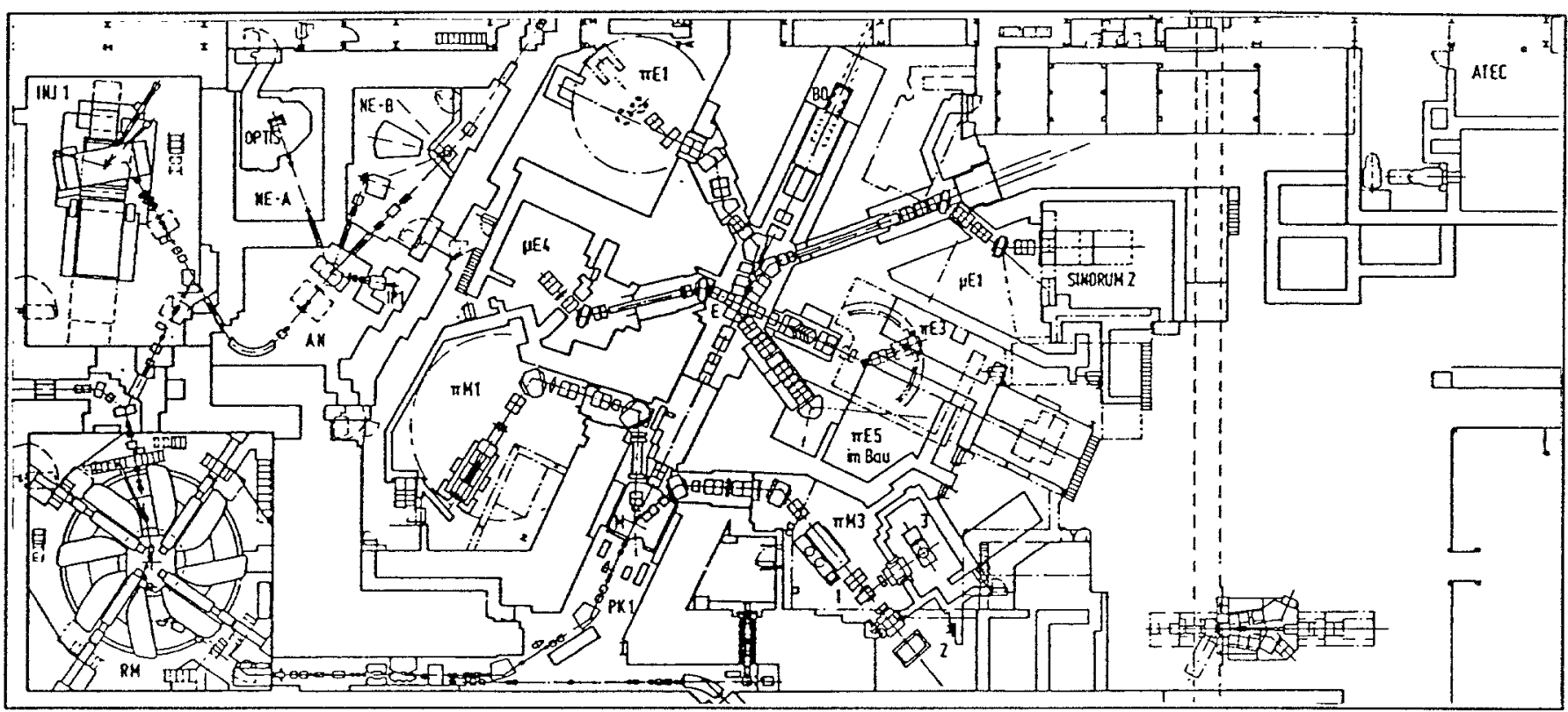

Fig. 1. Layout of the experimental hall

Table 1. Summary of expected muon fluxes and beam properties after the shut-down 1990-1991 from the various beam lines at 1 mA primary beam current

\begin{tabular}{llllll}
\hline$\mu^{+}$ & $\begin{array}{l}\text { mom. } \\
\mathrm{MeV} / \mathrm{c}\end{array}$ & $\begin{array}{l}\text { flux } 1 \mathrm{~mA} \\
\text { at }\end{array}$ & $\begin{array}{l}\delta p / p \\
\text { FWHM }\end{array}$ & $\begin{array}{l}\text { spot size } \\
\mathrm{cm}^{2}\end{array}$ & pol. \\
\hline \hline $\mathrm{E} 1$ & $40-125$ & $\begin{array}{l}2 \times 10^{8} \\
\text { at } 125 \mathrm{MeV} / \mathrm{c}\end{array}$ & $3 \%$ & $3 \times 2$ & $75 \%$ \\
\hline$\mu \mathrm{E} 4$ & $30-100$ & $\begin{array}{l}4 \times 10^{6} \\
\text { at } 50 \mathrm{MeV} / \mathrm{c}\end{array}$ & $3 \%$ & $6 \times 4$ & $75 \%$ \\
\hline$\pi \mathrm{E} 1$ & $5-30$ & $\begin{array}{l}2 \times 10^{6} \\
\text { at } 28 \mathrm{MeV} / \mathrm{c}\end{array}$ & $0.8 \%$ & $1.5 \times 2$ & $>95 \%$ \\
\hline$\pi \mathrm{E} 3$ & $5-30$ & $\begin{array}{l}3 \times 10^{7} \\
\text { at } 28 \mathrm{MeV} / \mathrm{c}\end{array}$ & $1 \%$ & $2 \times 3$ & $>95 \%$ \\
\hline$\pi \mathrm{E} 5$ & $5-30$ & $\begin{array}{l}2 \times 10^{8} \\
\text { at } 28 \mathrm{MeV} / \mathrm{c}\end{array}$ & $2 \%$ & $6 \times 4$ & $>95 \%$ \\
\hline$\pi \mathrm{M} 3$ & $5-30$ & $\begin{array}{l}4 \times 10^{6} \\
\text { at } 28 \mathrm{MeV} / \mathrm{c}\end{array}$ & $0.2 \%$ & $2 \times 2$ & $>95 \%$ \\
\hline
\end{tabular}

\begin{tabular}{llllll}
\hline$\mu^{-}$ & $\begin{array}{l}\text { mom. } \\
\mathrm{MeV} / \mathrm{c}\end{array}$ & $\begin{array}{l}\text { flux } \\
\text { at } 1 \mathrm{~mA}\end{array}$ & $\begin{array}{l}\delta p / p \\
\text { FWHM }\end{array}$ & $\begin{array}{l}\text { spot size } \\
\mathrm{cm}^{2}\end{array}$ & pol. \\
\hline \hline$\mu \mathrm{E} 1$ & $40-125$ & $\begin{array}{l}6 \times 10^{7} \\
\text { at } 125 \mathrm{MeV} / \mathrm{c}\end{array}$ & $3 \%$ & $3 \times 2$ & $75 \%$ \\
\hline$\mu \mathrm{E} 4$ & $30-100$ & $\begin{array}{l}1 \times 10^{6} \\
\text { at } 50 \mathrm{MeV} / \mathrm{c}\end{array}$ & $3 \%$ & $6 \times 4$ & $75 \%$ \\
\hline$\pi \mathrm{E} 1$ & $5-280$ & $\begin{array}{l}4 \times 10^{7} \\
\text { at } 100 \mathrm{MeV} / \mathrm{c}\end{array}$ & $0.8 \%$ & $1.5 \times 2$ & (var.) \\
\hline$\pi \mathrm{E} 3$ & $5-150$ & $\begin{array}{l}3 \times 10^{7} \\
\text { at } 100 \mathrm{MeV} / \mathrm{c}\end{array}$ & $1 \%$ & $2 \times 3$ & (var.) \\
\hline$\pi \mathrm{E} 5$ & $5-120$ & $\begin{array}{l}2 \times 10^{8} \\
\text { at } 100 \mathrm{MeV} / \mathrm{c}\end{array}$ & $2 \%$ & $6 \times 4$ & (var.) \\
\hline$\pi \mathrm{M} 3$ & $5-300$ & $\begin{array}{l}4 \times 10^{6} \\
\text { at } 100 \mathrm{MeV} / \mathrm{c}\end{array}$ & $0.2 \%$ & $2 \times 2$ & (var.) \\
\hline
\end{tabular}

\section{Muon beam $\mu \mathrm{E} 4$}

There is only one minor change in the $\mu \mathrm{E} 4$ channel: we installed a removable degrader made of $2.5 \mathrm{~cm}$ Beryllium at the entrance of the superconducting solenoid. This, by reducing the pion decays in the injection system, will increase the rate of very low energy muons and makes the channel suitable for feeding the phase space compression device (PSC) proposed by D. Taqqu [5].

\section{Pion Beam $\pi \mathrm{E} 3$}

This channel was an excellent surface muon beam in the past and will be so in future. The rates are high because they are proportional to the projection of the production target seen by the channel and the $\pi \mathrm{E} 3$ looks to it under an angle of 90 degrees and images more than half of the $6 \mathrm{~cm}$ long target.

The main design criterium was a chromatic high resolution final beam spot matching the Low Energy Pion Spectrometer (LEPS), but an achromatic tune is possible for muon physics with bigger acceptance than in the high resolution mode [6].

\section{Pion beam $\pi \mathrm{E} 5$}

The $\pi E 5$ is a new channel looking to the target from the back under an angle of 175 degree. The first focussing element of the $\pi \mathrm{E} 5$ is a bending magnet, which deflects the proton beam too. This limits the beam momentum to $120 \mathrm{MeV} / \mathrm{c}$ because at higher values it is no more possible to correct the proton deflections, but anyhow the pion production cross section at backward angles will fall steeply at higher momenta. 


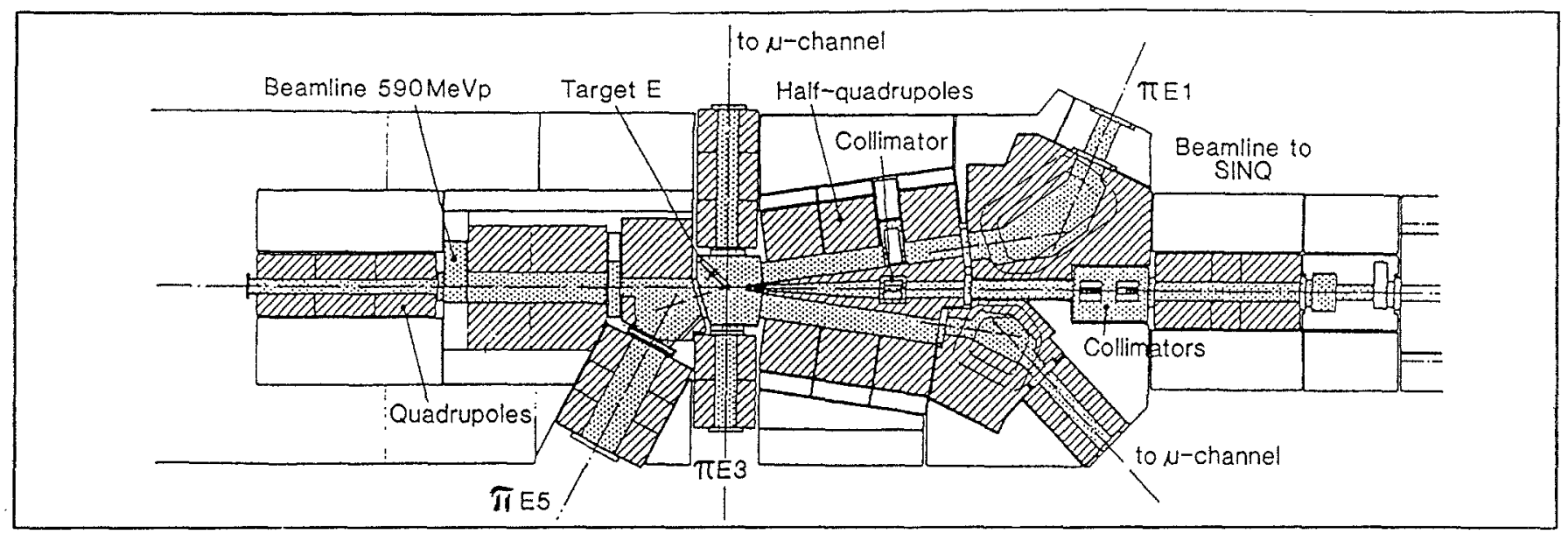

Fig. 2. Layout of the target E region

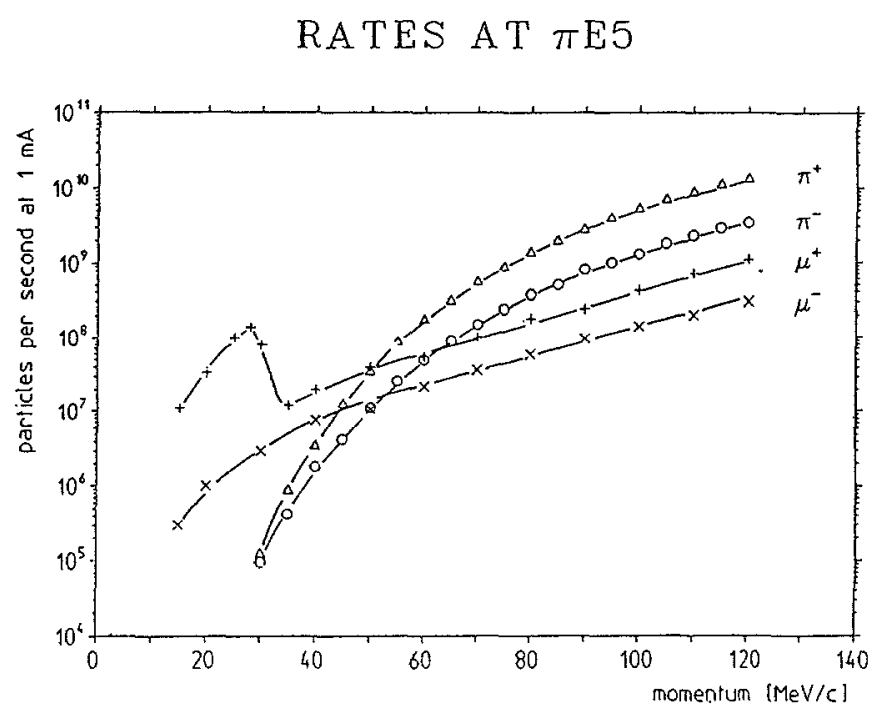

Fig. 3. Caculated particle fluxes from the new $\pi \mathrm{E} 5$ channel at $1 \mathrm{~mA}$ primary proton beam current.

This channel has an angular acceptance of $150 \mathrm{msr}$, which is five times bigger than in 'standard' beam lines, and transports a momentum band of $10 \%$ FWHM. To achieve this we had to develope special quadrupoles with an aperture radius of $20 \mathrm{~cm}$ and with built in octupole components for the correction of third order aberations. Together with the short channel length of 11 meter the big acceptance will give outstanding high pion rates (Fig. 3) [7]. To give high flexibility the beam line can serve two experimental ports just by switching the polarity of the last bending magnet.

This beam will be most suitable

1. for stopped pion experiments at highest,

2. for adaption to the planned "pion-muon-converter", a special, $6.5 \mathrm{~m}$ long superconducting solenoid to produce a high purity $\mu$-minus beam with a pion contamination of $10 \mathrm{E}-8$ and with rates of the order $10 \mathrm{E} 8 / \mathrm{sec}$ in SINDRUM II, and

3. for injection into a future "low energy muon facility" which will produce muons at $\mathrm{keV}$ energies $[8,9]$.

\section{Outlook}

The reconstruction of the target station $E$ and of the secondary beams, except the new $\pi \mathrm{E} 5$, was finished by summer 1991. At that time only part of the enlarged accelerating RF-power is available, allowing an average proton current of approx. $500 \mu \mathrm{A}$ until the end of 1991 . Two short shutdowns at the beginning and at the end of 1992 are planned for the installation of the last parts of the acceleration system.

\section{References}

1. W. Fischer, Proc. 10th Meeting of the Int. Coll. on Advanced Neutron Sources, Los Alamos, 1988.

2. W. Joho, Proc. 11th Int. Conf. on Cycl. and their Appl., Tokyo, 1986, p. 31.

3. U. Schryber et al., Proc. 12th Int. Conf. on Cycl. and their Appl., Berlin, 1989.

4. D. George et al., Proc. 9th Int. Conf. on Mag. Tech., Zürich, 1985, p. 185.

5. D. Taqqu, Nucl. Instr. \& Meth., A247 (1986) 288.

6. F. Foroughi, The new $\pi \mathrm{E} 3$ : Achromatic Beam Optic, PSITechnical Note (1990), unpublished.

7. D. Renker et al., PSI Annual Report 1989, Annex I, p. 12.

8. See contributions to these proceedings by $D$. Taqqu and $E$. Morenzoni.

9. R. Abela et al., PSI Annual Report 1990, Annex I, p. 19

This article was processed using Springer-Verlag TEX Z.Physik C macro package 1991

and the AMS fonts, developed by the American Mathematical Society. 